\title{
Capacity Building for Sustainable Development: The Experience of Developing a Professional Diploma in Energy-Efficient Buildings
}

\author{
Ahmed S. Muhaisen ${ }^{1}$, Omar S. Asfour ${ }^{2} \&$ Matthias Schuss $^{3}$ \\ ${ }^{1}$ Department of Architecture, Islamic University of Gaza, Gaza City, Palestinian Territories \\ ${ }^{2}$ Department of Architecture, King Fahd University of Petroleum and Minerals, Dhahran, Saudi Arabia \\ ${ }^{3}$ Department of Building Physics \& Building Ecology, Vienna University of Technology, Vienna, Austria \\ Correspondence: Ahmed S. Muhaisen, Department of Architecture, Islamic University of Gaza, Gaza City, P.O. \\ Box 108, Palestinian Territories. Tel: 970-8264-4400. E-mail: amuhaisen@iugaza.edu.ps
}

Received: June 24, 2019

doi:10.5539/jsd.v12n4p187
Accepted: July 9, 2019 Online Published: July 30, 2019

URL: https://doi.org/10.5539/jsd.v12n4p187

\begin{abstract}
The implementation of energy-efficiency measures in building design is an essential strategy in the context of sustainable development; however, this requires plans for capacity building to improve the capabilities of engineers working in the construction sector. The role of higher education institutions in this context is essential. In the Gaza Strip, the issue of energy efficiency in buildings has gained increased attention on undergraduate and graduate education levels; however, there is a lack of specialised programs to address this issue based on a holistic design approach. Thus, a survey was carried out with local specialists and engineers using a workshop and questionnaire to investigate the potential of a proposed professional diploma in energy-efficient buildings. The study used a mixed qualitative and quantitative approach to examine the importance, topics and potential impact of this program in the Gaza Strip. The study concluded that such a program is essential for Gaza considering the ongoing electricity shortage and the future need for sustainable development plans. The study recommends implementation, evaluation and development of such a program in the rest of Palestinian governorates as a response to the current and future energy challenges.
\end{abstract}

Keywords: energy efficiency, sustainability, buildings, engineering education, professional diploma, Gaza

\section{Introduction}

Several concerns face the world nowadays regarding the sustainability of energy supplies. These supplies mainly depend on the burning of fossil fuel to secure the required amount of energy. Given that more than one-third of the global final energy consumption applies to the construction and operation of buildings (IEA, 2019), there is an urgent need to develop and implement sustainable development plans that promote the use of green building practices. These plans are essential to meet the requirements of the growing green building markets in the developed countries (Chan, Qian \& Lam, 2009). They are also essential to avoid the rapid deterioration of energy supplies, which is expected to negatively affect all aspects of our lives. It will also affect the ability of future generations to meet their own needs of energy supplies, which is the main pillar of the sustainable development concept (WCED, 1987). This is already the case in the Gaza Strip, which suffers from an acute energy shortage. The Gaza Strip forms the southern governorates of the Palestinian Territories and is characterized by a short, mild and rainy winter; and a long, hot and dry summer (ARIJ, 2003). This increases building energy demand, mainly for cooling in summer. The main source of energy in this regard is electricity, which is either imported or locally produced in Gaza's only power plant. Unfortunately, the Gaza Strip has been facing an ongoing electricity shortage for more than a decade, which has reduced productivity and negatively affected people's quality of life. Figure 1 shows the monthly availability of electricity (hours per day) in Gaza. It is possible to notice a continuous fluctuation, which reflects the instability of electricity supplies. A significant increase could be noticed at the end of 2018 due to the subsidized fuel supplies, which are unsustainable and could not be relied upon in the long run.

One essential measure to mitigate the implications of this electricity crisis is to promote the use of energy-efficient practices in the local built environment. Despite the fact that these practices will not solve the problem, they could be considered as a sustainable and positive behavioural transformation strategy even if 
electricity supplies improved in the future. The Gaza Strip has considerable renewable energy sources, especially solar energy. There are also several opportunities related to the implementation of energy-saving measures, including passive cooling and heating and natural lighting. This makes the implementation of energy-efficiency measures in building design a promising strategy to reduce the amount of energy needed to operate buildings; however, this requires an active engagement of higher educational institutions in the required capacity building of the concerned stakeholders, including engineers. Capacity building in the context of sustainable development is a broad concept and can encompass several activities. It could be described as 'building abilities, relationships and values that will enable organizations, groups and individuals to improve their performance and achieve their development objectives' (UNEP, 2006, p. 2).

Globally, the need for energy education increases day by day; however, studies on energy education are still limited (Acikgoz, 2011). Strengthening people's understanding of energy-efficient buildings and the related issues of environmental education has rarely been discussed (Juan \& Chao, 2015). Energy topics, such as energy conversion, distribution and storage, could be found in several engineering disciplines, including mechanical, chemical and electrical. Addressing these issues has become an essential part of the expected learning outcomes and the required conditions of degree accreditation. This should be done in a practice-oriented way in order to satisfy the competences needed in the market. In this context, graduates' competitiveness in the market is seen as a main indicator of the quality of engineering educational programs (Minin, Vyuzhanina, 2014). The role of accreditation agencies essential in this regard (Jolly \& Mahieu, 2016). For example, satisfying the issues of sustainability and energy efficiency is essential in the context of NAAB accreditation of architecture programs (NAAB, 2015). However, it has not been until recently that energy use in buildings has been offered in separate courses. For example, courses such as Sustainable Architecture or Energy-Efficient Building Design are now common in the undergraduate and graduate levels. A bachelor's degree in renewable energy, which tackles the topics of energy engineering and focuses on the area of renewable energy, is also common. Diploma and short-term courses are also available and can effectively help to address engineers regarding energy sustainability issues in buildings and introduce the emerging technologies in this regard. All these options are useful and could be used in multi-disciplinary educational environments (Molthan-Hill et al., 2019).

In the Gaza Strip, the role of higher education institutions takes several forms, including organizing training programs (Muhaisen \& Asfour, 2017), developing special courses in some related disciplines such as architecture (Muhaisen, 2016) and civil engineering (Kevern, 2011) or developing specialized programs on the undergraduate or graduate levels. For example, Al-Azhar University in Gaza offers a BSc program in Renewable Energy (Al-Azhar University, 2017). Some institutions offer accredited applied diploma in this regard; this includes University College of Science and Technology - Khan Younis (CST, no date), which offers a diploma program in Solar Energy Technology. However, there is a need in Gaza for a postgraduate educational program on a professional level that tackles the topic of energy-efficient buildings considering its theoretical and practical aspects. This should be based on a holistic approach that focuses not only on solar energy but also on other aspects of energy-efficient design, such as green building materials, energy-efficient systems and building operation management. Thus, this study aims to investigate the potential of such a program in the Gaza Strip and examine its importance. Further, it is the goal of this study to document the experience of the design process of a professional diploma in Energy-Efficient Buildings in terms of need assessment, content development and expected impact. This is explained in the following sections. 


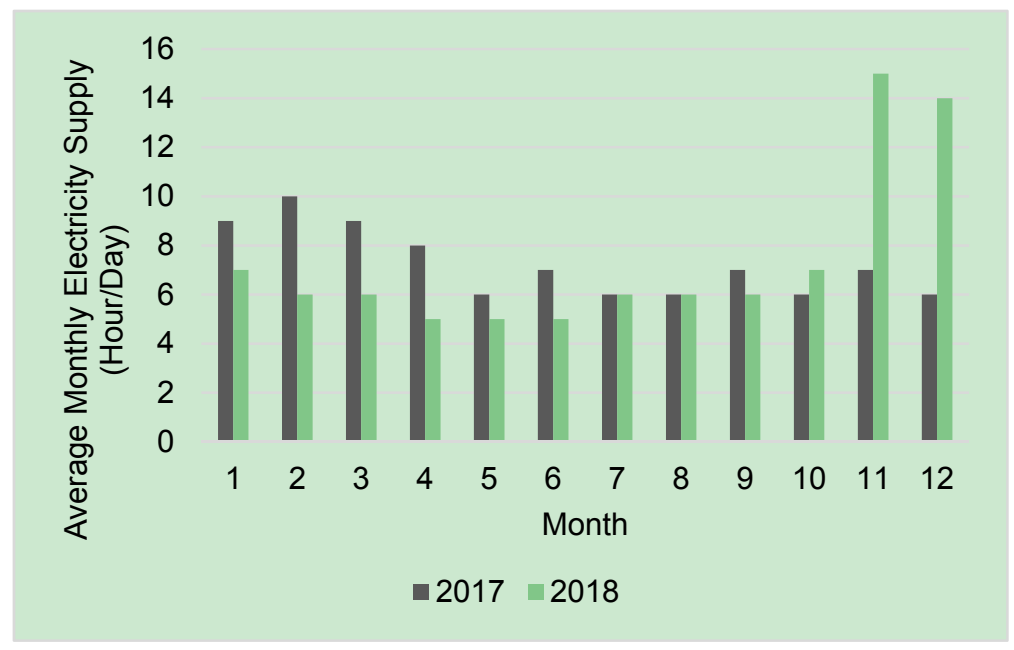

Figure 1. The monthly availability of electricity in Gaza (OCHA, 2019)

\section{Method}

This study is based on a mixed qualitative and quantitative approach that has been used to achieve the study aim discussed above. A literature review was first carried out to introduce the topic and the research problem. The study then used two main tools to collect the required data and triangulate the results. The first is a face-to-face workshop to host some senior engineers and experts in the field and collect their opinions and feedback. Workshops are useful to obtain the feedback of a selected group of experts on a specific issue, where face-to-face discussions allow for the exchange of ideas and perspectives and produce qualitative data and insights. The workshop was held in January 2018 in Gaza, and hosted 20 experts consisting of academic staff members and representatives of local ministries, municipalities, NGOs and private organizations. The participants were carefully selected based on their relevant experience and active engagement in academia and practice. The participants were firstly divided into five focus groups and used specially prepared forms to address the different aspects of the proposed program 'Professional Diploma in Energy-Efficient Buildings' to be offered by the Islamic University of Gaza (IUG). Following this, each focus group presented its findings to the rest of the groups for discussion. The workshop discussed the need of the proposed program, its objectives, importance, expected competencies and entry requirements as well as its proposed topics and courses. Finally, findings were discussed and documented.

The second tool is a questionnaire directed to the local engineers in the Gaza Strip which aimed to triangulate the workshop results through assessing the need and impact of the proposed program. The Gaza Strip Engineering Syndicate was established in 1976, and, according to its website (Gaza Strip Engineering Syndicate, 2015), the number of registered engineers in the Syndicate was 11,000 in 2015. Assuming an annual increase of 500 engineers, the current number of registered engineers in the Syndicate today is assumed to be approximately 14,000. Thus, the required sample size is 95 sampling units assuming a confidence level of $95 \%$ and a confidence interval of $10 \%$ (Creative Research Systems, 2012). Data collection continued for a week in June 2019 until the required sample size was achieved. The questionnaire included an introduction to explain its purpose, some questions about respondents' personal information and three sections to examine the proposed program need, its content and its expected impact, respectively. The questionnaire was prepared using Google Forms and electronically distributed using email lists of the IUG and the Gaza Strip Engineering Syndicate in addition to the relevant social media groups. The number of successfully completed forms was 96 , and results were analysed using the SPSS program using means, the relative importance index (RII) and one- and independent-sample t-tests.

\section{Results and Discussion}

\subsection{The Workshop}

The workshop moderator started the meeting by presenting the need for capacity buildings in the field of energy-efficient buildings in the Gaza Strip in order to enhance the sustainability of the built environment. A possible initiative in this context is to propose a professional diploma, which was the main recommendation of a previous workshop (Muhaisen \& Asfour, 2017). The main advantage of the intended diploma is to enhance the practical competencies of its candidates in addition to their theoretical background. The discussion included several issues using two discussion modes: the focus group and the public discussion. The workshop moderator 
divided the participants into five focus groups to address the different aspects of the proposed program using specially prepared forms. After that, each focus group presented its findings to the rest of the groups for discussion. The workshop moderator recorded and refined the findings, which were as follows.

The first issue in the discussion was the local need of the proposed program from the participants' points of view. The attendees agreed on the need to develop such a diploma program in the field of energy-efficient buildings and justified their feedback on the special energy conditions in the Gaza Strip and the lack of professionals in this field. They emphasized the need for a program that is mainly based on a practical and technical approach rather than mere theoretical approach. The proposed program gains its importance from possessing the following attributes:

- Being the first of its kind in the field of energy efficiency in the Gaza Strip

- Being based on a practical approach to training

- Being expected to create job opportunities in the field of energy-efficient buildings

The participants agreed that the proposed professional diploma is a specialized program which requires a satisfactory background in engineering; therefore, interested candidates should have accomplished at least a bachelor's degree in engineering in any related discipline or an intermediate diploma with practical experience for a certain period. The participants also discussed the proposed program objectives and agreed on the following:

- Capacity building of local professionals working in the field of energy-efficient buildings

- Promoting the principles of energy efficiency in buildings to contribute to the protection of the environment

- Enhancing creativity and innovation in the field of energy-efficient buildings

- Opening up new markets for energy efficient resources and materials

- Enhancing the integration of multiple engineering disciplines

As for the expected competencies, the participants stated that the diploma graduates are expected to gain the following competencies:

- Designing energy-efficient buildings

- Selecting and using suitable energy efficient materials

- Choosing and sizing renewable energy applications in buildings

- Estimating the costs of the new construction of energy-efficient buildings in addition to the retrofit of the existing building

- Using related computer simulation programs

As for the program content, the participants classified the required courses under four main areas: building design, building materials, renewable energy and energy efficient technology. They suggested the following courses:

- Energy-Efficient Buildings Design: to develop the theoretical and practical skills of students in the field of the architectural design of energy-efficient buildings

- Ventilation and Lighting: to examine the effective use of natural ventilation and lighting in buildings as an energy-saving strategy

- Thermal Analysis of Buildings: to discuss the principles of thermal analysis of buildings

- Building Techniques and Materials: to discuss energy-efficient building techniques and materials

- Renewable Energy Techniques: to discuss renewable energy systems and how to use them in buildings

- Solar Energy: to focus on solar energy techniques in buildings and determine whether to produce electricity or thermal energy

- Management and Audit of Buildings' Energy: to develop students' abilities to manage and audit energy consumption in buildings in order to increase their efficiency

- Energy-Efficient Urban Planning: to discuss energy efficient urban planning as a step ahead of building design

- Buildings' Environmental Impact Assessment: to discuss the environmental impact of energy-efficient buildings 
- Special Issues: to cover emerging topics that are not offered in the courses above

- Graduation Project: to develop the research and practical capabilities of students in the field of design and implementation of energy-efficient buildings

In addition, the following elective courses were proposed:

- Green Building Assessment Systems: to discuss green building assessment through studying some common international and regional systems

- Computer Applications: to develop students' skills in using various computer programs related to the environmental performance of buildings

- Green Economy: to discuss the principles of green economy and how to enhance it in the energy-efficient buildings industry

\subsection{The Questionnaire}

As explained in Sections 2 and 3.1, this questionnaire aims to triangulate the observations made by the consulted experts regarding the proposed program "Professional Diploma in Energy-Efficient Buildings". The questionnaire included some questions regarding the respondents' personal information followed by three sections to examine the proposed program's need and its content and expected impact. An analysis of respondents' personal data shows a good diversity in sampling units' characteristics, as $61.5 \%$ of the respondents were males and $38.5 \%$ were females. The sample represented some diversity in educational qualification, as well, as $52 \%$ of them hold a bachelor's degree, $40 \%$ hold a master's degree and $8 \%$ hold a Ph.D. The respondents' number of years of experience also varied; $23 \%$ of respondents have less than 2 years of experience, $21 \%$ have 2 to less than 5 years, $22 \%$ have 5 to less than 10 years and $34 \%$ have 10 and more years of experience. As for their specialties, the majority of respondents (73\%) were architects, $15 \%$ were civil engineers and the remainder had other different specialties. This may reflect the attractiveness of the proposed program to architects, as it focuses on buildings in terms of design and operation.

The first section aimed to examine the need for capacity building in the field of energy efficiency in the Gaza Strip, including the proposed professional diploma program from the respondents' points of view. This section included five statements, as shown in Table 1. Respondents were asked to express their agreement level on the listed statements using a five-point Likert scale. It could be noticed that RII values in all statements are relatively high, i.e. above 0.6. This shows that respondents generally believe that there is a need in the Gaza Strip for specialized education programs in the field of energy-efficient buildings and that the proposed professional diploma is a practical multi-discipline option in this context. Some respondents justified their answers as follows:

- This program is expected to contribute to the formulation of an energy-saving policy in the Gaza Strip construction sector

- This approach effectively links architectural education to practice

- The program focuses on practical competencies

- It is essential for those working in engineering projects that require experts in the field of green buildings

Furthermore, responses to these questions could be used to examine the following assumption (null hypothesis): 'There is no need in the Gaza Strip for the proposed professional diploma in energy-efficient buildings'. A one-sample t-test was used to examine the above-mentioned null hypothesis. The mean value of respondents' responses to each question and then for all the questions in this section were estimated. The total mean value was compared the mid-value of the five-point Likert scale, i.e. 3 to determine if there is any statistically significant difference between these two values. The total significance probability (Sig.) value for this section of the questionnaire was 0.0 . This is less than the significance level $(\alpha \leq 0.05)$, which means that the null hypothesis cannot be accepted. This further means that the respondents believe that there is a need for the proposed program in the Gaza Strip. Using an independent-sample t-test, the mean value of male and female responses in this section of the questionnaire were 4.3 and 4.4, respectively. The Sig. value was 0.34 , which is higher than the significance level. This means that there is no significant difference between male and female responses regarding the need for capacity building in the field of energy efficiency in the Gaza Strip, including the proposed professional diploma program. 
Table 1. Respondents' answers on the questions related to the program need

\begin{tabular}{llcc}
\hline No. & Statement & $\begin{array}{c}\text { Mean } \\
(0-5)\end{array}$ & $\begin{array}{c}\text { RII } \\
(0-1)\end{array}$ \\
\hline 1 & $\begin{array}{l}\text { There is a need in the Gaza Strip for specialized education programs in the } \\
\text { field of energy-efficient buildings. }\end{array}$ & 4.5 & 0.91 \\
2 & These programs are essential to improve local engineers' capacity in this field. \\
3 & $\begin{array}{l}\text { A professional diploma is a practical option in this context, as it combines } \\
\text { theoretical and practical aspects. }\end{array}$ & 4.5 & 0.90 \\
4 & I would apply for such a program if I had the opportunity to do so. & 0.87 \\
5 & I think this program would serve several engineering disciplines. & 3.9 & 0.79 \\
All Statements & 4.2 & 0.85 \\
\hline * Mean is significant at $\alpha \leq 0.05$ & 4.3 & 0.86 \\
\hline
\end{tabular}

The second section aimed to explore the importance of the proposed content of the program for the Gaza Strip from the respondents' points of view. Respondents were asked to evaluate the importance of each course proposed by the experts (as explained in Section 3.1) using a three-point Likert scale (high, medium, low). Table 2 shows that the respondents deemed almost all courses important, which is in agreement with the workshop recommendations. Using RII, the most important courses from the respondents' points of view were Ventilation and Lighting, Solar Energy and Renewable Energy Techniques. The least important course was Special Issues, possibly because it has no specified topics.

Table 2. Importance level of the different courses of the proposed program from the respondents' points of view

\begin{tabular}{llcrcc}
\hline \multirow{2}{*}{ No. } & Topic & \multicolumn{3}{c}{ Responses for Each Importance } & RII \\
\cline { 3 - 4 } & & Level (\%) & $(0-1)$ \\
\hline 1 & Energy-Efficient Buildings Design & Medium & Low & \\
2 & Ventilation and Lighting & 83 & 16 & 1 & 0.94 \\
3 & Thermal Analysis of Buildings & 76 & 21 & 3 & 0.91 \\
4 & Green Building Techniques and Materials & 71 & 27 & 2 & 0.90 \\
5 & Renewable Energy Techniques & 85 & 13 & 2 & 0.94 \\
6 & Solar Energy & 86 & 14 & 0 & 0.95 \\
7 & Management and Audit of Buildings' Energy & 76 & 23 & 1 & 0.92 \\
8 & Energy Efficient Urban Planning & 70 & 27 & 3 & 0.89 \\
9 & Buildings' Environmental Impact Assessment & 66 & 32 & 2 & 0.88 \\
10 & Special Issues & 26 & 64 & 10 & 0.72 \\
\hline
\end{tabular}

The third section aimed to explore the expected impact of the proposed program from the respondents' points of view. This section included six statements, as shown in Table 3. Respondents were asked to express their agreement level on the listed statements using a five-point Likert scale. It could be noticed that the RII values in all statements are relatively high. This shows that respondents generally believe that the proposed program is expected to have a positive impact on the Gaza Strip, including capacity building in the field of energy efficiency, alleviating the ongoing energy shortage and improving urban sustainability. Some respondents justified their answers as follows:

- The program will face the challenge of securing the required tools and technical resources at the beginning

- Such a program needs support from concerned authorities so that it could achieve the expected impact

- The trend of green buildings in the Gaza Strip is expected to gain more attention in the future, which increases 
the potential impact of the program considering the problems of pollution and resources scarcity

Similar to Section 1 of the questionnaire, responses to these questions could be used to examine the following assumption (null hypothesis): "There is no expected positive impact of the proposed professional diploma on the practices related to energy-efficient buildings in the Gaza Strip". A one-sample t-test was used to examine the above-mentioned null hypothesis. The total Sig. value for this section of the questionnaire was 0.0 ; this is less than the significance level $(\alpha \leq 0.05)$, which means that the null hypothesis cannot be accepted. This also means that the respondents believe that there is an expected positive impact of the proposed program on energy efficiency status in buildings in the Gaza Strip. Using an independent-sample t-test, the mean values of male and female responses in this section of the questionnaire were 4.2 and 4.3, respectively. Furthermore, the Sig. value was 0.53 , which is higher than the significance level. This means that there is no significant difference between male and female responses regarding the expected impact of the proposed program in terms of capacity building of local engineers and promotion of energy-efficient buildings in the Gaza Strip.

Table 3. Respondents' answers on the questions related to the expected impact of the program

\begin{tabular}{llcc}
\hline No. & Statement & $\begin{array}{c}\text { Mean } \\
(0-5)\end{array}$ & $\begin{array}{c}\text { RII } \\
(0-1)\end{array}$ \\
\hline 1 & $\begin{array}{l}\text { The proposed program is expected to contribute to building the capacity of local } \\
\text { engineers in the field of energy-efficient buildings. }\end{array}$ & 4.3 & 0.87 \\
2 & $\begin{array}{l}\text { Graduates of the proposed program are expected to play an active role in } \\
\text { mitigating the energy crisis in the Gaza Strip through the design and construction } \\
\text { of energy-efficient buildings. }\end{array}$ \\
3 & 4.1 & 0.81 \\
$\begin{array}{l}\text { The proposed program is expected to contribute to the promotion and application } \\
\text { of energy-efficient buildings on the ground. }\end{array}$ & 4.2 & 0.84 \\
$4 \quad \begin{array}{l}\text { The proposed program will ensure better integration between practice and } \\
\text { academia. }\end{array}$ & 4.1 & 0.83 \\
$\quad \begin{array}{l}\text { Developing the proposed professional diploma and, as a result, training a number } \\
\text { of engineers will contribute to improving urban sustainability in the Gaza Strip. }\end{array}$ & 4.2 & 0.84 \\
$\begin{array}{l}\text { The proposed professional diploma will contribute to building the capacity of the } \\
\text { Islamic University and improving the professional and specialized services it } \\
\text { provides to the community. }\end{array}$ & 4.3 & 0.87 \\
All Statements & 4.2 & 0.84 \\
\hline * Mean is significant at $\alpha \leq 0.05$ & & \\
\hline
\end{tabular}

\subsection{Program Finalisation and Accreditation}

Based on the above-mentioned recommendations, the IUG team prepared a final proposal and submitted it to the Palestinian National Board for Accreditation and Quality. The program has been reviewed and granted a special accreditation for the 2019/20 academic year (IUG, 2019). IUG will offer and manage the program through the IUG Community Development Institute in cooperation with the Faculty of Engineering.

\section{Conclusion}

Improving the energy efficiency of new and retrofitted buildings increasingly attracts the attention of researchers and practitioners in the field of construction. It forms a global challenge considering the rapid depletion of fossil fuels and the environmental impacts associated with its use. This necessitates the proper implementation of the concepts of energy efficiency in buildings; however, this requires the capacity building of the concerned stakeholders, including engineers of different disciplines. The role of education and higher education is essential in this regard. In the Gaza Strip, this issue is gaining increasing attention in the higher educational institutions in several forms. One available option in this regard that is still lacking is to offer a professional diploma in energy-efficient buildings that includes a comprehensive theoretical and practical background in this field. This study documented the experience of the design process of this diploma in terms of need assessment, content development and expected impact. To investigate these aspects, the study surveyed local experts through face-to-face workshops, including multiple focus groups. It also surveyed local engineers through a 
questionnaire. The study was carried out considering the experience and current conditions of the Gaza Strip. However, it was possible to conclude many recommendations and useful observations related to energy education that could be considered in other places of the world.

The study concluded that there is a need for capacity building in the field of energy efficiency in the Gaza Strip, including the proposed professional diploma program. This program is expected to have a positive impact on the Gaza Strip, including alleviating the ongoing energy shortage through implementing the principles of energy efficiency in buildings and improving urban sustainability in the Gaza Strip, in general. In this context, the problem of energy shortage could be considered as an opportunity that could be invested to encourage people implementing the concepts of energy-efficient buildings. This trend in engineering education is essential for Gaza considering the current and future need for sustainable development plans. This study recommends implementation, evaluation and development of such a program in the rest of the Palestinian governorates in response to the current and future energy challenges. The study also recommends expanding the presented investigation on regional and international levels to develop a conceptual framework that could be implemented in professional educational programs development in the field of energy-efficient buildings.

\section{Acknowledgments}

The authors would like to thank the APPEAR program and the Austrian Development Cooperation for funding this study through the project "Capacity Building for Energy-Efficient Buildings Towards a Sustainable Built Environment in the Gaza Strip- Palestine (CBEEB, Ref. 231)" and coordinated by Vienna University of Technology, Austria, in partnership with the Islamic University of Gaza, Palestinian Territories.

\section{References}

Acikgoz, C. (2011). Renewable energy education in Turkey. Renewable Energy, 36, 608-611. https://doi.org/10.1016/j.renene.2010.08.015

Al-Azhar University-Gaza. (2017). Study Plan - Renewable Energy Engineering. Retrieved from http://www.alazhar.edu.ps/arabic/planforwebsit/Default.aspx?plan_no $=9186$

ARIJ, the Applied Research Institute - Jerusalem. (2003). Climatic zoning for energy efficient buildings in the Palestinian Territories (the West Bank and Gaza). Retrieved from http://arij.org/publications/papers.html

Chan, E. H. W., Qian, Q. K., \& Lam, P. T. I. (2009). The market for green building in developed Asian cities - the perspectives of building designers. Energy Policy, 37, 3061-3070. https://doi.org/10.1016/j.enpol.2009.03.057

Creative Research Systems. (2012). Sample Size Calculator. Retrieved from https://www.surveysystem.com/sscalc.htm

CST, University College of Science and Technology - Khan Younis. (n. d.). Solar Energy Technology Diploma. Retrieved from http://en.cst.ps/eng/index.php/speciality/esaa/solar-technology

Gaza Strip Engineering Syndicate. (2015). Retrieved from http://www.enggaza.ps/EngAssoc/EngAbout

IEA, International Energy Agency. (2019). Energy efficiency: Buildings. Retrieved from https://www.iea.org/topics/energyefficiency/buildings/

IUG, Islamic University of Gaza. (2019). Professional diploma in energy efficient buildings accredited now at IUG. Retrieved from http://www.iugaza.edu.ps/en/About-IUG/News/Details?id=26985

Jolly, A. M., \& Mahieu, L. (2016). How accreditation agencies can help the necessary change of HEIs towards sustainable development practices. International Journal of Engineering Pedagogy, 6(1), 29-34. http://dx.doi.org/10.3991/ijep.v6i1.5336

Juan, Y., \& Chao, T. (2015). Game-based learning for green building education. Sustainability, 7(5), 5592-5608. https://doi.org/10.3390/su7055592

Kevern, J. T. (2011). Green building and sustainable infrastructure: Sustainability education for civil engineers. Journal of Professional Issues in Engineering Education and Practice, 137(2). https://doi.org/10.1061/(ASCE)EI.1943-5541.0000048

Minin, C. M., \& Vyuzhanina, N. (2014). Practice-oriented learning as a way to meet employers' requirements to graduates. International Journal of Engineering Pedagogy, 4(2), 31-35. http://dx.doi.org/10.3991/ijep.v4i2.3440

Molthan-Hill, P., Worsfold, N., Nagy, G. J., Filho, W. L., \& Mifsud, M. (2019). Climate change education for 
universities: A conceptual framework from an international study. Journal of Cleaner Production, 226, 1092-1101. https://doi.org/10.1016/j.jclepro.2019.04.053

Muhaisen, A. (2016). The experience of developing a module on energy-efficient buildings for architecture students. Proceedings of the $6^{\text {th }}$ International Engineering Conference on Energy-efficient buildings, IUG, Gaza, 25-26 Oct., pp. 109-115.

Muhaisen, A., \& Asfour, O. (2017). Developing and evaluating training programs on energy-efficient building design: The IUG experience, Palestine. Journal of Engineering Research and Technology, 4(2), 43-47.

NAAB, National Architectural Accrediting Board. (2015). NAAB procedures for accreditation. Retrieved from https://www.naab.org/wp-content/uploads/2016/03/Full-Document.pdf

OCHA, the United Nations Office for the Coordination of Humanitarian Affairs. (2019). Gaza Strip electricity supply. Retrieved from https://www.ochaopt.org/page/gaza-strip-electricity-supply

UNEP, United Nations Environment Programme. (2006). Retrieved from https://www.unpei.org/sites/default/files/PDF/institutioncapacity/Ways-to-increase-effectiveness-SD.pdf

WCED, the World Commission on Environment and Development. (1987). Our common future. Retrieved from http://www.un-documents.net/wced-ocf.htm

\section{Copyrights}

Copyright for this article is retained by the author(s), with first publication rights granted to the journal.

This is an open-access article distributed under the terms and conditions of the Creative Commons Attribution license (http://creativecommons.org/licenses/by/4.0/). 